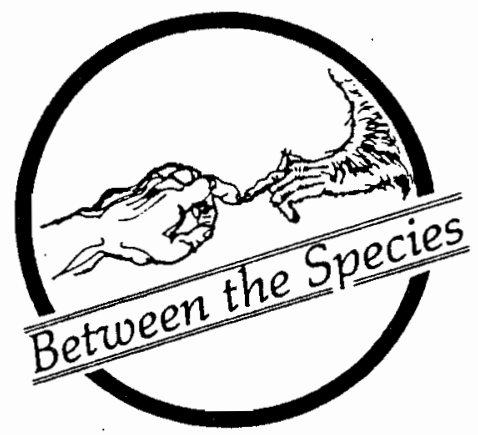

\title{
FRANCIS BACON: FATHER OF TECHNOCRACY
}

\section{Michael W. Fox}

The Humane Society of the United States

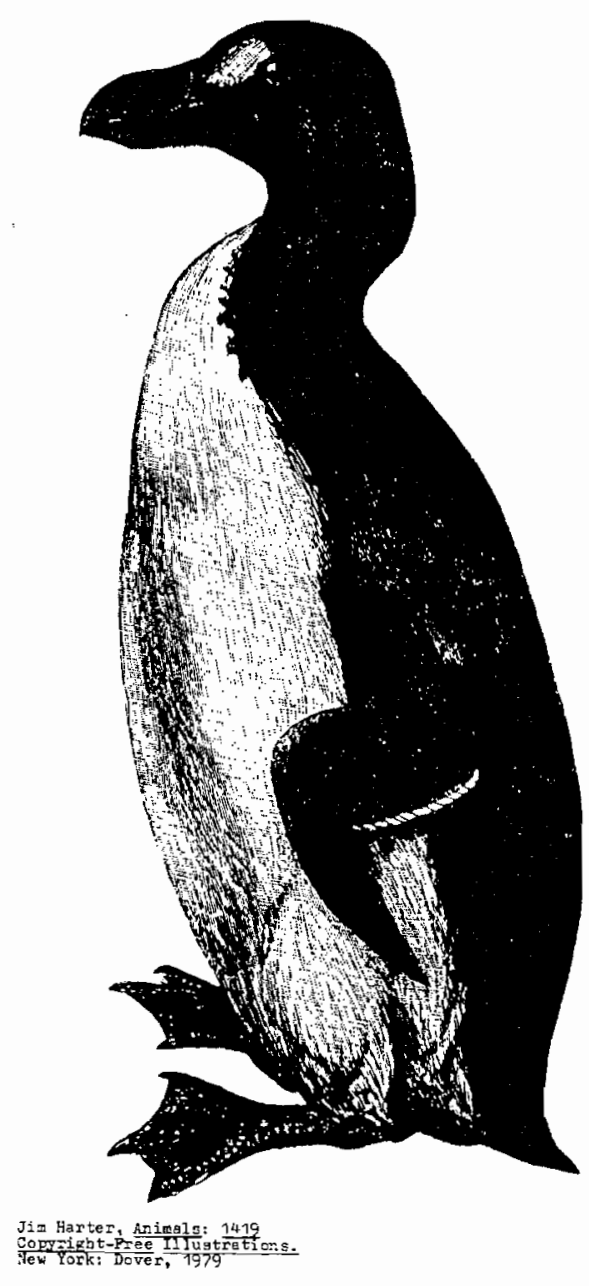

Francis Bacon $(1561$ - 1626) is the recognized philosopher of industrial science and Isaiah of the age of technocracy. It is on his ideas that the technocracy of today is largely founded, as well as the prevailing attitude toward nature as something to be improved upon for the betterment of society. Benjamin Farrington writes that Bacon "in challenging men - to win power over nature in order to improve the conditions of human life kindled a new conscience in mankind." While Bacon cautioned that "we cannot command nature without obeying her," he gave religious sanction to man's "endeavour to establish and extend the power and dominion of the human race itself over the universe" by seeing it as a sacred duty to improve and transform the conditions of human existence.

\section{HISTORY OF \\ IDEAS}

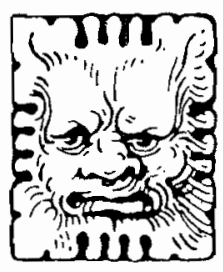


Now history teaches us that we cannot progress at Nature's expense and that we have failed to command her because we have not obeyed (i.e. fully understood and respected) her. Were Bacon alive today, he would surely be the first to see that his utopian philosophy has backfired, not simply because of human greed, ignorance and indifference but also because the industrial technocracy has not evolved in harmony with Nature. It has been built by a collective mentality that sees humanity as something separate from Nature and superior to the rest of creation. ${ }^{2}$ This is the fatal mistake of industrialized civilization, since it cannot prosper for long at Nature's expense, nor can it continue to exist separate from the natural world.

In pleading for the restoration of what he called "the commerce of the mind with things," because he felt that men should consult Nature rather than books to make progress in truth and in industry, Bacon made the acquisition of knowledge as power (regardless of the means whereby such knowledge was acquired) the supreme ethic. And since the attainment of such knowledge and its application to industrial science is the highest endeavor of humanity, it is of no ethical concern if harm is done to Nature in the process. In other words, Bacon established industrial progress as society's highest principle and prionity if not raison d'etre. Linked with his religious view of dominion as power over the universe and with the Protestant work ethic, Bacon's philosophy substituted the notion of industrial progress for the spiritual progress of the JudaeoChristian tradition. This substitution has persisted up to the present day. And in giving industrial progress religious sanction, scientific knowledge became the sacred authority for the new religion of an emerging technocracy.

While in Bacon's time traditional logic was concerned with the philosophy of eternal truths and with the essence of reality, Bacon reviled the lack of practical and material purpose in such thinking. $\mathrm{He}$ brought about a reform in logic with his emphasis upon inductive rather than deductive reasoning. And he saw progress in knowledge and progress in power as two aspects of the same process. He established the creed of the modern scientist whose quest for knowledge is the highest virtue, since it embodies truth and promises usefulness: "Truth therefore and utility are here the very same thing: and works themselves are of greater value as pledges of truth than as contributing to the comforts of life."

It should not be forgotten that Bacon wrote:
Man is the helper and interpreter of Nature. $\mathrm{He}$ can only act and understand insofar as by working upon her or by observing her he has come to perceive her order. Beyond that he has neither knowledge nor power. For there is no strength that can break the causal chain: Nature cannot be conquered but by obeying her. Accordingly these twin goals, human science and human power, come in the end to one.

While this statement might seem sympathetic toward Nature, it is doubtful Nature needs humanity as "helper and interpreter." This view planted the idea that it was humankind's divine role and duty to improve upon Nature. This is the arrogant pride of industrial man that presaged his fall and the crisis of modern industrial society, because Nature was exploited before being obeyed, i.e. respected and understood. We cannot blame Francis Bacon for this. It is more a product of human greed and hubris which his philosophy at worst inspired, even though he advised:

The secret workings of nature do not reveal themselves to one who simply contemplates the natural flow of events. It is when man interferes with nature, vexes nature, tries to make her do what he wants, not what she wants, that he begins to understand how she works and may hope to learn how to control her.

\section{In one of his last publications Bacon wrote:}

Without doubt we are paying for the sins of our first parents and imitating it. They wanted to be like Gods; we, their posterity, still more so. We create worlds. We prescribe laws to nature and lord it over her. We want to have all things as suits our fatuity, not as fits the Divine Wisdom, not as they are found in nature. We impose the seal of our image on the creatures and works of God, we do not diligently seek to discover the seal of God on things. Therefore not undeservedly have we again fallen from out dominion over the creation; and, though after the Fall of man some dominion over rebellious nature still remained - to the extent at least that it could be subdued and controlled by true and solid arts - even that we have for the most part forfeited by our pride, because we wanted to be like gods and follow the dictates of our own reason.

This statement is relevant today in that we have 
broken "the seal of God on things" (in atomic and genetic research especially) and now superimpose "the seal of our image on the creatures and works of God."

There is something distinctly disturbing about Bacon's works, aside from his loathing of Greek philosophy, particularly Plato and Aristotle. While he may be rightly regarded historically as the prophet and herald of industrial science, his vision failed to temper human arrogance and greed, in spite of, if not because of, his invocation of Divinity.

Philosopher Brian Klug writes that Bacon's talk of obeying nature rings rather hollow when we recall Bacon's "main objective to make nature serve the business and conveniences of man." Klug concludes that Bacon clearly invoked God's will and divine sanction to justify the scientific inquisition of nature. The use of animals in biomedical research today is presaged in Bacon's utopian saga New Atlantis, where the protagonist Father of Salomon's House proclaims "we also have parks and inclosures of all sorts of beasts and birds, which we use not only for view or rareness, but likewise for dissection and trials; that thereby we may take light what may be wrought upon the body of man....We try all poisons and other medicines upon them, as well as chirurgery as physic." Furthermore, the size, shape, color, behavior and reproduction of animals were altered and new species were created, a science-fiction vision which, through genetic engineering, is a reality today.

If anything, Bacon intensified the duality of Nature and Divinity, in one breath castigating humanity for wanting to be like Gods and in the next seeking to attain God-like dominion over "rebellious nature."

This schizoid worldview attracted those who sought to have God-like dominion over creation and profit at Nature's expense. Their lack of reverence for Nature is as evident today as it was in Bacon's philosophy, where reverence was reserved almost exclusively for humanity's "good works" and for its "commerce of the mind with things" in the name of industrial science and material progress. In so elevating humanity Bacon unwittingly sanctioned the rape of Nature. Had he a more compassionate and humble attitude toward Nature and all of God's creation, his zeal for the Protestant work ethic might have been tempered and the ethics of good husbandry and stewardship of Nature - so nascent in his writings - might have blossomed. Bacon's vision, like the science and industries of today, is imperfect because humankind is seen not as a cocreative participant and interlocutor between Divinity and Nature, and as a custodian of planet Earth, but as the lord and master: a God indeed.

\section{Notes}

\footnotetext{
1See Benjamin Farrington, Francis Bacon: Philosopher of Industrial Science. Henry Schuman, New York. 1949. All quotations in this paper are from this volume, unless otherwise noted.

2Ibid., Chapter 3.

3"Lab Animals, Francis Bacon and the Culture of Science," in Listening, Joumal of Religion and Culture, 18 (1983), pp. 54-72.
}

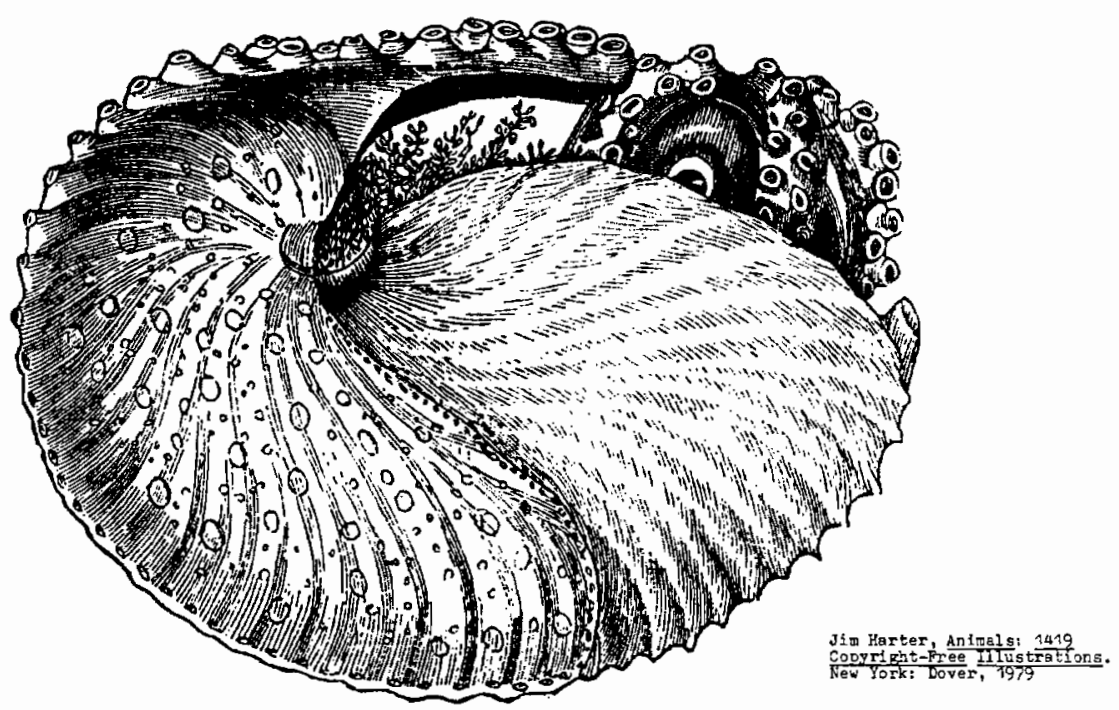

